The definition and analysis of capacity building in this chapter provides a foundation for understanding how capacity-building expectations and practices are fulfilled by organizations represented in the rest of this volume. The authors also address organizational change through their discussion of catalytic mechanisms.

\title{
Capacity building: A primer
}

\author{
David 7. Kinsey, 7. Russell Raker III
}

WHAT DOES IT MEAN to build capacity? Dozens of organizations say they are doing it, droves of CEOs and board members are attending seminars to learn how, and hundreds of consultants are offering to reveal the secrets of capacity building at the next board retreat. But what is it?

Fortunately, dictionary definitions of capacity are quite broadperhaps even ambiguous. This diversity of definitions helps to make the case that capacity and capacity building are complex, multifaceted concepts that embrace an organization's mission, history, style, commitment, organizational architecture, leadership, and more. The liberality and diversity of the definitions, however, continue to beg the questions, "What is capacity building?" "How might it apply to my organization?" and "How does it work?" 


\section{Conceptual foundations of capacity building}

Although the process of capacity building can take many forms, can be applied to many types and sizes of organizations, and can be implemented in an endless variety of ways, its conceptual foundations are always present.

\section{Validate mission}

A question commonly posed to governing boards by board officers, constituents, community leaders, and parent organizations is, "How well is the organization fulfilling its mission?" The capacitybuilding process begins by posing a much deeper, and often more troublesome, question: "Are we pursuing the right mission?" Does the organization fill a real need? Could another organization do the job better? Is the organization moving forward with a clear sense of purpose or simply continuing to exist through bureaucratic momentum? Particularly when the organization has a long history, was begun by an organizational champion, or supports a large workforce, all sorts of pressures may prevent this question from emerging.

\section{Reconsider the vision}

Vision statements, often regarded as "pie in the sky" by administrators and directors, are not often revisited once the board and staff have completed the task of constructing the first one. If the vision statement was, and perhaps still is, regarded as obligatory and fanciful-and therefore meaningless-it will not do much to encourage organizational growth and development. Vision statements may not always be within the immediate grasp of the organization to achieve, but they must at least be feasible, realistic, and possible, at least at some point in the foreseeable future.

\section{Reaffirm values}

Values do not often get the attention they deserve in the missionvision-values triad. If the values read like pabulum tastes (bland- to everybody but babies), they are probably not worth much. When board members confront important issues, do the value statements make an appearance? If not, they may be absent, weak, or forgotten. 
If the values do not pop up when tough decisions are on the table, it is likely that they no longer reflect the thinking of the leadership.

\section{Develop resources}

It is almost always true that resources do not simply materialize. Most often, they must be developed. That is, the board must identify all possible sources, evaluate the potential of each source, set strategies for capture, and then do the necessary work to ensure that the resources become available to the organization. There must be alignment between sources and strategies. If the organization will be depending on philanthropy for a large share of its operating revenue, does the board express a willingness to be engaged in fundraising? Do they expect the staff to raise funds without their assistance? Are the projected revenues realistic when considering the time allocation, experience, and the relationship with constituencies? Are government sources dependable over the long term? Are parent organizations willing to maintain or even increase their financial commitments? Answers to questions such as these will determine to what extent increases in organizational capacity are reasonable.

\section{Set strategies}

Capacity building demands experience in thinking and working strategically. If the organization has not been engaged in annual strategic planning, the unfamiliar process of enlarging capacity could create an organizational collapse. If the fellow who cuts the grass focuses on the lawn just ahead of the mower, the cut is crooked and the job is performed inefficiently. Keep your eye on a distant point and the mower swath is straight. Strategic planning is just like that. The shortsighted organization wastes time and energy by working with no plan or a day-to-day "plan."

\section{Ensure productivity}

Frequently monitoring performance and analyzing and correcting deviations is fundamental to capacity building. Faulty assumptions, environmental changes, and other unexpected barriers to planned performance must be dealt with quickly and decisively. Let a problem languish for a bit, and the error may be unrecoverable. It is not 
a sin to encounter obstacles to performance; not devising a timely alternative plan is.

How the mission is defined and how mission fulfillment is determined influence the possible outcomes when these fundamentals are applied to the process of organizational governance. For a few organizations, the process will reveal obsolete or faulty missions or expose a halfhearted board commitment that may contribute to extinguishing the organization. Most organizations, however, will discover that the capacity-building process reveals new possibilities, stimulates renewed leadership commitment at both the staff and board levels, and expands the universe of potential resources.

A few organizations (probably a very few) will be inspired to reinvent their organizations. For these organizations, the effect can be thoroughly transforming, and the transformation will take place in both the organizational structure and in many members of the board and staff.

The McKinsey Capacity Building Assessment Grid (McKinsey \& Company for Venture Philanthropy Partners, 2001) provides an eloquent framework for an in-depth, thorough evaluation. The matrix can subsequently be the basis for acting on the opportunities that the assessment initiative revealed.

For the group of organizations whose boards make the judgment that their organization should define the standard by which that type of organization is measured, yet more initiatives may come into play. Some of these will always be manifested in organizations that are thriving, growing, validating mission, and staying on mission. To thrive, however, the level of commitment on the part of board, volunteer leadership, and staff must be very high. Once begun, the process can continue for as long as the organization wishes to identify as a high-performing organization.

\section{The monster called BHAG}

In their research for Built to Last (2002), Porras and Collins identify the "monster" many organizations fear most and avoid at all costs: the BHAG (Big Hairy Audacious Goal). Their description 
of a BHAG includes three defining characteristics: it has a long time frame (ten to thirty years or more); it is clear, compelling, and easy to grasp; and it connects to the core values and purpose of the organization. Examples of BHAGs are Starbucks' goal of becoming the world's best recognized brand name, Sony's 1950s BHAG to change the world's opinion about the quality of Japanese-made goods, and Nike's effort to eclipse its competitor, Adidas.

The BHAG is unique, say the authors, in that it is able to blend continuity with change. Employing it requires a bold approach. One powerful way of doing that, they assert, is to employ what they call catalytic mechanisms-engines for change.

\section{Catalytic mechanisms: Engines for change}

The nature of catalytic mechanisms, says Jim Collins (1999), is illustrated at the conclusion of Walden (1992), in which Henry David Thoreau writes, "If you have built castles in the air, your work need not be lost; that is where they should be: Now put the foundations under them" (p. 82). Collins goes on to describe BHAGs as a "company's wildest dreams" and catalytic mechanisms as their foundations. "Build them both," he advises (p. 82).

Collins (1999) identifies five characteristics of a catalytic mechanism. Our brief review of these characteristics and some examples of how they are articulated in organizations will provide a helpful introduction to them:

- A catalytic mechanism produces desired results in unpredictable ways. Traditionally designed management systems tend to strengthen bureaucracies.

Bureaucratic systems can be productive, but they are always limited by predictability and conformity. Organizations excel when people are allowed to do unexpected things- to show initiative and creativity and to "throw away the script."

- A catalytic mechanism distributes power for the benefit of the overall system, often to the great discomfort of those who traditionally bold power. 
Catalytic mechanisms force the right things to happen, even when those in leadership (power) benefit from another outcome. The impact of this characteristic, says Collins (1999), is that "it subverts the default, knee-jerk tendency of bureaucracies to choose inaction over action, status quo over change, and idiotic rules over common sense." Distributing leadership power is largely unfamiliar in most organizations, but when this happens, "vast reservoirs of energy and competence flow" (p. 76).

- A catalytic mechanism has teeth.

The process of creating and implementing catalytic mechanisms carries a number of built-in properties that push the organization toward mission fulfillment. When catalytic mechanisms are functioning, nonproductivity is literally squeezed out. Productivity is rewarded on both an individual and a team basis, and there are strong incentives not to let the team down.

- A catalytic mechanism ejects viruses.

Collins (1999) asserts that the old adage that "people are your most important asset" is wrong. The right persons, that is, those who share the core values and naturally express the character and attitude of the organization, are its best assets. Finding those individuals, and creating catalytic mechanisms that so strongly reflect core values that those who do not share them will not be hired or will leave, is the real challenge.

- A catalytic mechanism produces an ongoing effect.

Collins (1999) is careful to contrast catalytic mechanisms with a close relative, the catalytic event. Speeches, rallies, and campaignsall can be useful, but if their effect is short term, they are merely catalytic events. Staffs have become immune to programs that are built around buzzwords and fads. If there is a probability that a change initiative cannot produce high productivity over a period of years, it does not qualify as a catalytic mechanism.

Catalytic mechanisms can exist in multiples, should evolve over time, and are best created with broad employee input. Because they have transformational potential, organizations should develop and implement them with serious thought and extreme care. 


\section{Quality: Capacity building's yardstick}

Whether it is a shirt, a bell pepper, an automobile, or a service, we all want quality. Most of us believe that we can define quality, but depending on what the organization is, what the product or service is, or what our expectations are, the definitions can be quite different. Good construction, freshness, flavor, durability, dependability, style, customer delight: all these and dozens more relate in one way or another to what we call quality. If the combination of these factors also comes with low price, we are even happier (witness the popularity of off-price retailers T. J. Maxx, Marshalls, Ross, and the "wholesale club" retailers Costco and Sam's Club).

For organizations that wish to build capacity, concerns about quality are among the most important considerations. In some organizations, quality improvement opportunities come knocking. For Florida's children's services agency, a current quality improvement opportunity is to find dozens of children the system has lost. But most organizations' own perceptions about their quality, and the perceptions of clients or the public, will be considerably less dramatic. Nevertheless, in the long run, they may be just as important in that they may have a profound effect on the organization's future through a catastrophic failure or a slowly building collection of client dissatisfactions. The organ transplant debacle at Duke University Hospital in which the young recipient died is a sad but powerful example of a catastrophic outcome in the absence of a simple, glaringly obvious verification of donor-recipient blood type matching.

Until the 1980s, quality management was rare in all except product-driven organizations, and even there the scope of what should be considered in the "quality" column was limited. The work of Joseph M. Juran, founder of the Juran Institute, led to the concept of Total Quality Management and created a formal approach to defining, managing, and improving quality in a range of settings, from manufacturing to service organizations to educational and health care institutions. The idea that doing a thing well could be substituted for culling out the substandard-that is, 
achieving built-in quality-is a better approach that is easy to accept but harder to achieve and maintain.

The Juran Institute, among others with a similar focus, offers progressively more sophisticated training in quality management for CEOs and board leaders committed to building organizational capacity and effectiveness. For executives who wish to lead their organizations through a capacity-building transformation, this type of training is an imperative.

\section{Integration and collaboration}

When a youngster whom I know formed her first sentence, it was, "I can do it myself." Her early predisposition for fierce independence persisted as she went into the first grade and will no doubt be an asset to her as she moves through the grade levels and someday enters a career field. Especially for youngsters with these traits, lessons about teamwork and the benefit of collaboration must begin in the early grades.

Many institutions-perhaps even most institutions-however, have not gotten the message that there is strength in being outwardly focused. Self-reliance can easily become egotism; "maintaining values" can turn into isolationism; an obsessive pursuit of "excellence" can eventually create an elitist organization. Organizations interested in building capacity will need to find ways to engage others in partnerships. Transforming an organization is difficult, if not impossible, to achieve without collaboration and integration.

\section{Becoming and staying a bigh-performing organization}

Doing all that we have already outlined here will automatically include the essential ingredient for success as a high-performing organization-listening. This element of capacity building cannot 
be emphasized enough. The answers to many critical questions that the organization needs to know are frequently overlooked. Boards often despise the idea that staff members' experience and training could be valuable; it would not occur to managers in many organizations to solicit an opinion from the rank and file; and seeking opinions from constituents or the public might reveal that the organization lacks adequately prepared leadership. It almost seems silly to see these admissions in print, yet they are too common in many organizations today, even leading ones.

\section{The bottom line}

Organizations that wish to engage in the process of capacity building and transformation-those that decide to experience the personal and corporate satisfaction of building and achieving the status of a high-performing organization-will find that there are many pathways leading to that destination. It may seem paradoxical to suggest it, but organizations moving toward that goal will probably use many of those pathways. The directors, staff, and others will not march along in perfect cadence on a single path. The talents, time, experience, education, and degree of commitment to the mission, vision, and values of the organization on the part of those who would undertake the journey will bring diversity to the effort, along with some wrong turns, conflict, and dropouts.

Organizations whose leadership chooses to work toward superior performance must realize that both reward and risk will emerge in the process.

Management staffs that have difficulty coping with anything less than perfection in the capacity-building process will face many disappointments along the way. Individuals whose need for validation and approval extends much beyond the satisfaction of leading an organization that is delivering maximum benefit to its constituents should think twice before triggering the capacitybuilding process. 


\section{References}

Collins, J. C. "Turning Goals into Results: The Power of Catalytic Mechanisms." Harvard Business Review, July-Aug. 1999, pp. 71-82.

Collins, J. C., and Porras, J. I. Built to Last: Successful Habits of Visionary Companies. New York: HarperCollins, 2002.

McKinsey \& Company for Venture Philanthropy Partners. Effective Capacity Building in Nonprofit Organizations. [http://vppartners.org/learning/reports/ capacity/capacity.html]. 2001.

Thoreau, H. D. Walden. Boston: Charles E. Tuttle Co., 1992.

DAVID J. KINSEY is an advancement officer at Loma Linda University and Medical Center in southern California.

J. RUSSELL RAKER III is an advancement officer at Loma Linda University and Medical Center in southern California. 